\title{
Pathological features of lymph nodes around inferior mesenteric artery in rectal cancer: a retrospective study
}

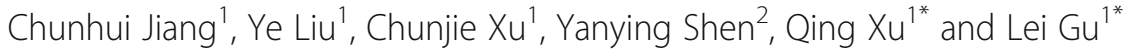

\begin{abstract}
Objective: This study aimed to explore the pathological characteristics of lymph nodes around inferior mesenteric artery in rectal cancer and its risk factors and its impact on tumor staging.

Methods: 485 rectal cancer patients underwent proctectomy surgery were collected in this study. Clinical features of patients, including gender, age, BMl, tumor size, pathological type, differentiation, nerve invasion, lymph nodes, tumor marker, and pathological examinations, were analyzed.

Results: A total of 485 cases were included in this study. There were 29 cases with IMA-LN metastasis; the metastasis rate was 5.98\% (29/485). Positive IMA-LNs were associated with distance from anal verge, CEA, pathological type, differentiation, nerve invasion, T stage, and N stage. Multivariate analysis showed that distance from anal verge, CEA level, differentiation, and T stage were independent risk factors for positive IMA-LNs.

Conclusion: Distance from anal verge, CEA level, differentiation, and T stage were independent risk factors for positive IMA-LNs. No skip metastasis occurred in IMA-LNs. We should choose the appropriate surgical methods to achieve better oncological results and reduce the incidence of postoperative complications.
\end{abstract}

Keywords: Rectal cancer, Lymph nodes metastasis, High ligation, Inferior mesenteric artery, Pathological features

\section{Introduction}

In the treatment principle of colorectal cancer, there are great differences between the East and the West. For locally advanced rectal tumors, the US guidelines recommend TME surgery on sequence of neoadjuvant chemotherapy, while for resectable colon tumors, neoadjuvant chemotherapy plus intestinal resection and full dissection of regional lymph nodes are recommended. However, Asian doctors represented by China, Japan, and South Korea advocated D3 lymphadenectomy based on Japanese guidelines. Therefore, whether to perform the third station lymph node dissection is controversial. As

\footnotetext{
*Correspondence: renjixuqing@163.com; renjigulei@163.com 'Department of Gastrointestinal Surgery, Renji Hospital, Shanghai Jiao Tong University School of Medicine, Shanghai 200127, China

Full list of author information is available at the end of the article
}

the core of the third station lymph nodes, the one around the root of inferior mesenteric artery (IMA$\mathrm{LNs})$, its impact on prognosis and the way of dissection have been the focus of research.

\section{Materials and methods Clinical samples}

From Jan. 2018 to Dec. 2020, we performed a retrospective analysis of patients who were eligible to receive proctectomy surgery in the Department of Gastrointestinal Surgery, Renji Hospital, Shanghai Jiao Tong University School of Medicine. Inclusive criteria: no distant metastasis, no obstruction, no emergency surgery, no radiotherapy or chemotherapy and other anti-tumor treatment, no history of other malignant tumors, and no colorectal multiple primary cancer. Routine MR examinations were performed

(c) The Author(s). 2021 Open Access This article is licensed under a Creative Commons Attribution 4.0 International License, which permits use, sharing, adaptation, distribution and reproduction in any medium or format, as long as you give appropriate credit to the original author(s) and the source, provide a link to the Creative Commons licence, and indicate if changes were made. The images or other third party material in this article are included in the article's Creative Commons. licence, unless indicated otherwise in a credit line to the material. If material is not included in the article's Creative Commons licence and your intended use is not permitted by statutory regulation or exceeds the permitted use, you will need to obtain permission directly from the copyright holder. To view a copy of this licence, visit http://creativecommons.org/licenses/by/4.0/ The Creative Commons Public Domain Dedication waiver (http://creativecommons.org/publicdomain/zero/1.0/) applies to the data made available in this article, unless otherwise stated in a credit line to the data. 
before surgery, and clinical TN staging was performed. The study was approved by the Research Ethics Committee of Renji Hospital and carried out in accordance with the ethical standards formulated in the Helsinki Declaration.

Surgical procedure:

1) General anesthesia, adjust the patient's position, and laparoscopic exploration.

2) Mobilize the sigmoid colon along the inferior mesenteric artery, find the Toldt's fascia, and mobilize the lateral peritoneum.

3) Separate the root of the naked inferior mesenteric artery and clean the lymph nodes at the root of the inferior mesenteric artery.

4) Ligate the artery after being clamped by Hem-Olock at the root of IMA and IMV about $2 \mathrm{~cm}$, resected IMA-LNs.

5) Naked the intestine $10 \mathrm{~cm}$ proximal of the tumor and $5 \mathrm{~cm}$ at the distal of the tumor and transected, removed the tumor specimen, and anastomosed by circular stapler.

\section{Pathological analysis}

The specimens were dissected by the surgeon after operation, and all the accessible lymph nodes were routinely submitted for examination. Pathological examination was performed by pathology department of our hospital. Routine examination included HE stained of tumor sections and lymph nodes and microsatellite instability (expression of mismatch repair protein MLH1, MSH2, MSH6, and PMS2) and ras gene mutation (K-ras, N-ras and BRAF gene mutations). Pathological staging was performed according to American Joint Committee on Cancer (AJCC) 8th Edition TNM staging system.

\section{Statistical analysis}

All categorical data were counted as cases or percentages, and continuous data were expressed as mean \pm SD. Statistical analyses were conducted by Statistical Product and Service Solutions (SPSS) 20.0 (Chicago, IL, USA) and GraphPad Prism 5 software. Categorical data were analyzed using the chi-squared $\left(\chi^{2}\right)$ test or Fisher's exact test. Multivariate analysis was performed through multivariate Cox proportional hazards regression analysis. Statistical significance was reached at a value of $(\mathrm{P}<$ 0.05).

\section{Results}

Positive rate of IMA-LN

According to the above inclusion criteria, a total of 485 cases were enrolled in this study. All patients successfully completed IMA-LN dissection. In this study, IMALN metastasis (positive) was defined as at least one positive lymph node was found in this area. In IMA-LNs, a total of 1043 lymph nodes were found, of which 38 were positive (3.6\%). The rate of IMA-LNs lymph node metastasis rate was defined as IMA-LN metastasis cases/ total number of cases. Among all the included cases, there were 29 cases with IMA-LN metastasis; the metastasis rate was $5.98 \%(29 / 485)$.

\section{IMA-LN and clinical characters}

In this study, we found that positive IMA-LNs were not associated with gender, age, or body mass index (BMI), but related to the distance from anal verge. All patients were routinely examined for tumor markers, including carcinoembryonic antigen (CEA), carbohydrate antigen 19-9 (CA19-9), and carbohydrate antigen 72-4 (CA72-4). We found that positive IMA-LNs were not associated with CA19-9 or CA72-4, but related to CEA (Table 1).

\section{IMA-LN and pathological parameters}

Positive IMA-LNs were not associated with tumor size, lymph nodes harvest number, microsatellite status, or ras phenotype, but related to pathological type, differentiation, and nerve invasion. And positive IMA-LNs were related to $\mathrm{T}$ stage and $\mathrm{N}$ stage, as shown in Table 2.

Table 1 IMA-LN and clinical characters

\begin{tabular}{|c|c|c|c|c|c|}
\hline & \multirow{2}{*}{$\begin{array}{l}\text { Case } \\
\text { (n) }\end{array}$} & \multicolumn{2}{|l|}{ IMA-LN } & \multirow[t]{2}{*}{$x^{2}$ value } & \multirow[t]{2}{*}{$P$ value } \\
\hline & & Metastasis (n) & $\begin{array}{l}\text { Metastasis } \\
\text { rate }(\%)\end{array}$ & & \\
\hline \multicolumn{6}{|l|}{ Gender } \\
\hline Male & 296 & 16 & 5.4 & 0.445 & 0.505 \\
\hline Female & 189 & 13 & 6.9 & & \\
\hline \multicolumn{6}{|l|}{ Age (years) } \\
\hline$\leq 60$ & 171 & 10 & 5.8 & 0.008 & 0.929 \\
\hline$>60$ & 314 & 19 & 6.1 & & \\
\hline \multicolumn{6}{|c|}{ BMI $\left(\mathrm{kg} / \mathrm{m}^{2}\right)$} \\
\hline$\leq 25$ & 298 & 19 & 6.4 & 0.216 & 0.642 \\
\hline$>25$ & 187 & 10 & 5.3 & & \\
\hline \multicolumn{6}{|c|}{ Distance from anal verge $(\mathrm{cm})$} \\
\hline$\leq 10$ & 322 & 13 & 3.7 & 6.428 & $0.011^{*}$ \\
\hline$>10$ & 163 & 16 & 9.2 & & \\
\hline \multicolumn{6}{|c|}{ CEA (ng/ml) } \\
\hline$\leq 5$ & 202 & 5 & 2.5 & 7.561 & $0.006^{*}$ \\
\hline$>5$ & 283 & 24 & 8.5 & & \\
\hline \multicolumn{6}{|c|}{ CA19-9 (U/ml) } \\
\hline$\leq 27$ & 213 & 10 & 4.7 & 1.115 & 0.291 \\
\hline$>27$ & 272 & 19 & 7.0 & & \\
\hline \multicolumn{6}{|c|}{ CA72-4 (U/ml) } \\
\hline$\leq 6.9$ & 304 & 17 & 5.6 & 0.217 & 0.641 \\
\hline$>6.9$ & 181 & 12 & 6.6 & & \\
\hline
\end{tabular}

${ }^{*} P<0.05$, the difference was statistically significant 
Table 2 IMA-LN and pathological parameters

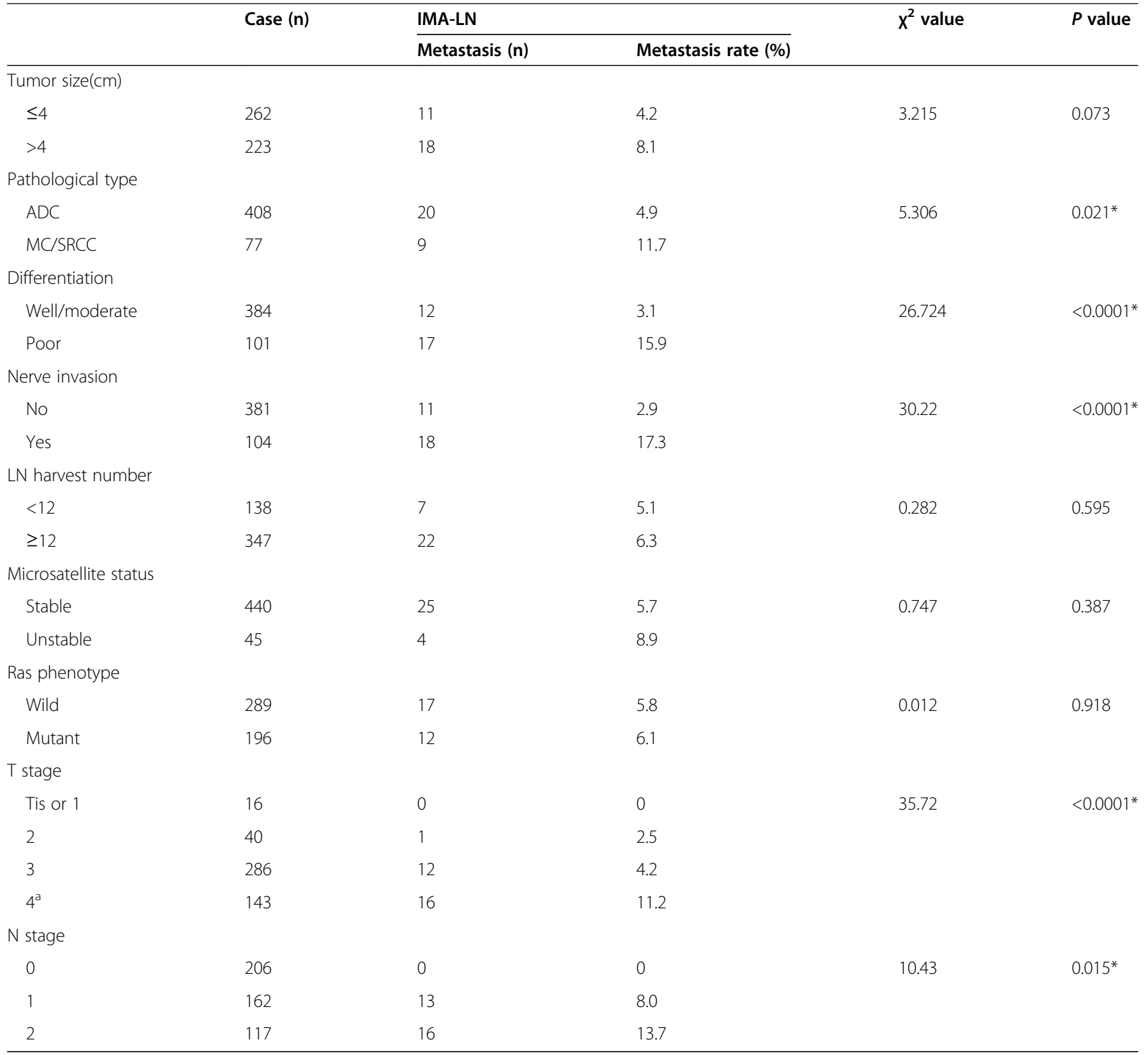

$A D C$ adenocarcinoma, $M C$ mucinous carcinoma, SRCC signet ring cell carcinoma ${ }^{*} P<0.05$, the difference was statistically significant

${ }^{a}$ Including high rectal cancer and preoperative MRI prompt T3

Interestingly, there was no case of IMA-LN positive without paracancerous lymph node metastasis, which means no case of skip metastasis.

Further, eight variables with $\mathrm{P}<0.1$ (distance from anal verge, CEA level, tumor size, pathological type, differentiation, nerve invasion, $\mathrm{T}$ stage, and $\mathrm{N}$ stage) were included in the multivariate analysis. The analysis showed that distance from anal verge, CEA level, differentiation, and $\mathrm{T}$ stage were independent risk factors for positive IMA-LNs (Table 3).

\section{Discussion}

Lymph node metastasis is the most common and main metastasis pathway of colorectal cancer, and it is also an important indicator of staging and prognosis of colorectal cancer [1, 2]. The value of lymph node dissection around root of IMA is still disputed. Many studies have reported that D3 dissection can reduce paraaortic recurrence and systemic metastasis [3], and improve the prognosis $[4,5]$. On the other side, some studies believe that the lymph node metastasis rate of IMA-LNs is relatively 
Table 3 Multivariate logistic regression analysis for risk factors on IMA-LN metastasis

\begin{tabular}{|c|c|c|c|c|c|c|}
\hline & Regression coefficients & Standard error & Wald value & OR & $95 \% \mathrm{Cl}$ & $P$ value \\
\hline Distance from anal verge & -1.545 & 0.718 & 4.633 & 0.213 & $0.052-0.871$ & $0.031^{*}$ \\
\hline CEA level & -2.721 & 0.980 & 7.710 & 0.066 & $0.010-0.049$ & $0.005^{*}$ \\
\hline Tumor size & -0.481 & 0.777 & 0.383 & 0.618 & $0.135-2.835$ & 0.536 \\
\hline Pathological type & 0.003 & 0.806 & 0.000 & 1.003 & $0.207-4.869$ & 0.997 \\
\hline Differentiation & -3.913 & 0.714 & 30.050 & 0.020 & $0.005-0.081$ & $0.000^{*}$ \\
\hline Nerve invasion & -1.484 & 0.845 & 3.084 & 0.227 & $0.043-1.118$ & 0.079 \\
\hline T stage & -2.169 & 1.078 & 3.883 & 0.121 & $0.015-1.045$ & $0.048^{*}$ \\
\hline N stage & -0.672 & 0.586 & 1.316 & 1.958 & $0.621-6.167$ & 0.251 \\
\hline
\end{tabular}

${ }^{*} P<0.05$, the difference was statistically significant

low, even after resection this kind of patients suggest poor prognosis, so it is of less significance to be resected [6-8].

Our study showed that the positive rate of IMA-LN was related to distance from anal verge, CEA level, tumor size, pathological type, differentiation, nerve invasion, $\mathrm{T}$ stage, and $\mathrm{N}$ stage. The result is similar to the previous reports [9]. Sun et al. [10] pointed out that for rectal cancer, neoadjuvant chemoradiotherapy can reduce the lymph node metastasis rate of IMA-LNs. For the patients who received neoadjuvant chemoradiotherapy, the location of the lesion above peritoneal reflexes, low degree of tumor differentiation and high preoperative serum CEA level were the risk factors of positive IMA-LNs. Nagasaki et al. [11] found that for patients with stage III colon cancer, serum CEA level, T stage, and number of lymph node dissection will significantly affect the positive situation of the third station lymph nodes (including IMA-LNs). Multivariate logistic regression analysis showed that only four factors (distance from anal verge, CEA level, differentiation, and T stage) were independent risk factors for positive IMA-LNs. There is no clear evidence that different locations of the lesion in the rectum affect the lymph node metastasis rate. It is worth noting that the lymph node metastasis rate of sigmoid colon tumor is significantly higher than that of rectal tumor $[7,12]$.

The AJCC staging is determined by the number of lymph nodes rather than the distance from the tumor [13, 14]. There are few studies and reports about the effect of IMALNs on TNM staging [15]. The positive IMA-LNs can aggravate the severity of the original stage III patients $[16,17]$. Some surgeons believe that IMA-LNs metastasis can occur in T2, 3, 4 colorectal tumors, and there may be skip metastasis. Therefore, IMA-LNs should be routinely removed for colorectal tumors beyond T1 $[18,19]$. But in this study, we did not find $\mathrm{N}$ positive was caused by only IMA-LN, which means no skip metastasis. It also means that if IMA-LNs turn negative, TNM staging will not be reduced. Does it mean that IMA-LN is not the origination of metastasis, but just the destination or interchange station?
Whether lymph node dissection around IMA can benefit patients is still uncertain, which may be the reason why the guidelines differ in this respect. Since there is no clear evidence that D3 lymph node dissection can benefit patients, the European and American guidelines do not consider it necessary to perform routine third station lymph node dissection [20]. High ligation has been reported to be effective in oncology; it can reduce paraaortic recurrence and systemic metastasis and improve the prognosis of some patients [21]. But from the point of view of complications such as anastomosis leakage and postoperative physiological dysfunction, it seems that high ligation is slightly worse than low ligation [22, 23]. For laparoscopic or robotic assisted radical surgery for colorectal cancer, the guidelines are conservative and not recommended as a routine recommendation. Only doctors with relevant experience should be recommended. At the same time, tumor staging, lymph node metastasis, and surgical difficulty should be considered comprehensively [24]. Many studies think that there is no significant difference between high and low ligation [25-27]. In our study, from the pathological features, the benefit of high ligation with low tumor location is limited.

Although the range of lymphadenectomy is controversial in different guidelines, the importance of lymphadenectomy is consistent. According to Japanese Society for Cancer of the Colon and Rectum (JSCCR) guidelines for the treatment of colorectal cancer, IMA-LNs are defined as the lymph nodes from the root of IMA to the beginning of LCA and along the IMA [28-30]. Similarly, follow the principles of CME, the scope of dissection is around the root of IMA, but it often goes beyond the boundary in real operation. It is possible that part of the retroperitoneal tissue may be removed due to excessive traction. So we need further research to define such a region.

Distance from anal verge, CEA level, differentiation, and $\mathrm{T}$ stage were independent risk factors for positive IMA-LNs. No skip metastasis occurred in IMA-LNs. Surgeons should fully evaluate the above-related factors 
and choose the appropriate surgical methods in order to achieve better oncological results and reduce the incidence of postoperative complications. At present, there is no strong evidence of evidence-based medicine that IMA-LNs dissection can improve the prognosis of patients, but IMA-LN metastasis is a risk factor for poor prognosis. With the development of precision medicine, it is expected that new diagnostic techniques can accurately evaluate the status of lymph node metastasis before operation, and more high-quality multicenter randomized controlled trial is expected to guide clinical decision-making.

As a retrospective analysis, some limitations existed in this study. First, in this study, the sample size is limited. If the sample size is increased, more accurate conclusions can be drawn. Second, a variety of statistical methods can be used to analyze the data and mutually verify the results.

\section{Abbreviations}

IMA: Inferior mesenteric artery; IMV: Inferior mesenteric vein; LN: Lymph node; LCA: Left colonic artery; BMI: Body mass index

\section{Acknowledgements}

Not applicable.

\section{Authors' contributions}

$\mathrm{CHJ}$ and $\mathrm{YL}$ wrote the main manuscript and participated in the study design and data analysis. CJX and YYS analyzed and interpreted the patient data. QX and LG modified the article. LG was a major contributor in writing the manuscript. All authors read and approved the final manuscript.

\section{Funding}

This work was supported by National Natural Science Foundation of China (82072671) and Research Fund for medical engineering cross project of Shanghai Jiao Tong University (ZH2018ZDA08).

\section{Availability of data and materials}

The datasets used and analyzed during the current study are available from the corresponding author on reasonable request.

\section{Declarations}

\section{Ethics approval and consent to participate}

All patients provided written informed consent before the operation, and this study was approved by the ethics committee of our hospital (number of ethics approval: KY2019-014)

\section{Consent for publication}

Not applicable.

\section{Competing interests}

The authors declare that they have no competing interests.

\section{Author details}

${ }^{1}$ Department of Gastrointestinal Surgery, Renji Hospital, Shanghai Jiao Tong University School of Medicine, Shanghai 200127, China. ${ }^{2}$ Department of Pathology, Renji Hospital, Shanghai Jiao Tong University School of Medicine, Shanghai 200127, China.

Received: 3 March 2021 Accepted: 11 May 2021

Published online: 18 May 2021

\section{References}

1. Benson AB, Venook AP, Al-Hawary MM, Cederquist L, Chen YJ, Ciombor KK, et al. Rectal cancer, Version 2.2018, NCCN Clinical Practice Guidelines in
Oncology. J Natl Compr Canc Netw. 2018;16(7):874-901. https://doi.org/10. 6004/jncen.2018.0061.

2. Gao Z, Cao H, Xu X, Wang Q, Wu Y, Lu Q. Prognostic value of lymphovascular invasion in stage II colorectal cancer patients with an inadequate examination of lymph nodes. World J Surg Oncol. 2021;19(1): 125. https://doi.org/10.1186/s12957-021-02224-3.

3. Kang J, Hur H, Min BS, Kim NK, Lee KY. Prognostic impact of inferior mesenteric artery lymph node metastasis in colorectal cancer. Ann Surg Oncol. 2011;18(3):704-10. https://doi.org/10.1245/s10434-010-1291-x.

4. Slanetz CA Jr, Grimson R. Effect of high and intermediate ligation on survival and recurrence rates following curative resection of colorectal cancer. Dis Colon Rectum. 1997;40(10):1205-19. https://doi.org/10.1007/BF02055167.

5. Singh D, Luo J, Liu X-T, Ma Z, Cheng H, Yu Y, et al. The long-term survival benefits of high and low ligation of inferior mesenteric artery in colorectal cancer surgery: a review and meta-analysis. Medicine (Baltimore). 2017; 96(47):e8520. https://doi.org/10.1097/MD.0000000000008520.

6. Huh JW, Kim YJ, Kim HR. Distribution of lymph node metastases is an independent predictor of survival for sigmoid colon and rectal cancer. Ann Surg. 2012;255(1):70-8. https://doi.org/10.1097/SLA.0b013e31823785f6.

7. Rao X, Zhang J, Liu T, Wu Y, Jiang Y, Wang P, et al. Prognostic value of inferior mesenteric artery lymph node metastasis in cancer of the descending colon, sigmoid colon and rectum. Colorectal Dis. 2018;20(6): 0135-42. https://doi.org/10.1111/codi.14105.

8. Lee SH, Lee JL, Kim CW, Lee HI, Yu CS, Kim JC. Oncologic significance of para-aortic lymph node and inferior mesenteric lymph node metastasis in sigmoid and rectal adenocarcinoma. Eur J Surg Oncol. 2017;43(11):2076-83. https://doi.org/10.1016/j.ejso.2017.08.014.

9. Wang $X J$, Chi $P$, Lin HM, Lu XR, Huang $Y$, Xu ZB, et al. A scoring system to predict inferior mesenteric artery lymph node metastasis and prognostic value of its involvement in rectal cancer. Int J Colorectal Dis. 2014;29(3):293300. https://doi.org/10.1007/s00384-013-1816-4.

10. Sun $Y$, Chi $P$, Lin $H$, Lu X, Huang $Y, X u Z$, et al. Inferior mesenteric artery lymph node metastasis in rectal cancer treated with neoadjuvant chemoradiotherapy: Incidence, prediction and prognostic impact. Eur I Surg Oncol. 2017;43(1):85-91. https://doi.org/10.1016/j.ejso.2016.09.005.

11. Nagasaki T, Akiyoshi T, Fujimoto Y, Konishi T, Nagayama S, Fukunaga Y, et al. Prognostic impact of distribution of lymph node metastases in stage III colon cancer. World J Surg. 2015;39(12):3008-15. https://doi.org/10.1007/ s00268-015-3190-6.

12. Chin CC, Yeh CY, Tang R, Changchien CR, Huang WS, Wang JY. The oncologic benefit of high ligation of the inferior mesenteric artery in the surgical treatment of rectal or sigmoid colon cancer. Int J Colorectal Dis. 2008;23(8):783-8. https://doi.org/10.1007/s00384-008-0465-5.

13. Conci S, Ruzzenente A, Sandri M, Bertuzzo F, Campagnaro T, Bagante F, et al. What is the most accurate lymph node staging method for perihilar cholangiocarcinoma? Comparison of UICC/AJCC pN stage, number of metastatic lymph nodes, lymph node ratio, and log odds of metastatic lymph nodes. Eur J Surg Oncol. 2017;43(4):743-50. https://doi.org/10.1016/j. ejso.2016.12.007.

14. Doll D, Gertler R, Maak M, Friederichs J, Becker K, Geinitz H, et al. Reduced lymph node yield in rectal carcinoma specimen after neoadjuvant radiochemotherapy has no prognostic relevance. World J Surg. 2009;33(2): 340-7. https://doi.org/10.1007/s00268-008-9838-8.

15. Kim JC, Lee KH, Yu CS, Kim HC, Kim JR, Chang HM, et al. The clinicopathological significance of inferior mesenteric lymph node metastasis in colorectal cancer. Eur J Surg Oncol. 2004;30(3):271-9. https:/ doi.org/10.1016/j.ejso.2003.12.002.

16. Feng $H$, Zhao XW, Zhang Z, Han DP, Mao ZH, Lu AG, et al. Laparoscopic complete mesocolic excision for stage II/III left-sided colon cancers: a prospective study and comparison with D3 lymph node dissection. J Laparoendosc Adv Surg Tech A. 2016;26(8):606-13. https://doi.org/10.1089/ lap.2016.0120.

17. Uehara K, Yamamoto S, Fujita S, Akasu T, Moriya Y. Impact of upward lymph node dissection on survival rates in advanced lower rectal carcinoma. Dig Surg. 2007;24(5):375-81. https://doi.org/10.1159/000107779.

18. Gouvas N, Agalianos C, Papaparaskeva K, Perrakis A, Hohenberger W, Xynos E. Surgery along the embryological planes for colon cancer: a systematic review of complete mesocolic excision. Int J Colorectal Dis. 2016;31(9):157794. https://doi.org/10.1007/s00384-016-2626-2.

19. Li K, Chen D, Chen W, Liu Z, Jiang W, Liu X, et al. A case-control study of using carbon nanoparticles to trace decision-making lymph nodes around 
inferior mesenteric artery in rectal cancer. Surg Endosc. 2019;33(3):904-10. https://doi.org/10.1007/s00464-018-6384-9.

20. Shinagawa T, Tanaka T, Nozawa H, Emoto S, Murono K, Kaneko M, et al. Comparison of the guidelines for colorectal cancer in Japan, the USA and Europe. Ann Gastroenterol Surg. 2017;2(1):6-12. Published 2017 Dec 19. https://doi.org/10.1002/ags3.12047.

21. Matsuda K, Hotta T, Takifuji K, Yokoyama S, Oku Y, Watanabe T, et al. Randomized clinical trial of defaecatory function after anterior resection for rectal cancer with high versus low ligation of the inferior mesenteric artery. Br J Surg. 2015;102(5):501-8. https://doi.org/10.1002/bjs.9739.

22. Mari GM, Crippa J, Cocozza E, Berselli M, Livraghi L, Carzaniga P, et al. Low ligation of inferior mesenteric artery in laparoscopic anterior resection for rectal cancer reduces genitourinary dysfunction: results from a randomized controlled trial (HIGHLOW Trial). Ann Surg. 2019;269(6):1018-24. https://doi. org/10.1097/SLA.0000000000002947.

23. Fan YC, Ning FL, Zhang CD, Dai DQ. Preservation versus non-preservation of left colic artery in sigmoid and rectal cancer surgery: a meta-analysis. Int J Surg. 2018;52:269-77. https://doi.org/10.1016/j.ijsu.2018.02.054.

24. Vogel JD, Eskicioglu C, Weiser MR, Feingold DL, Steele SR. The American Society of Colon and Rectal Surgeons Clinical Practice Guidelines for the Treatment of Colon Cancer. Dis Colon Rectum. 2017;60(10):999-1017. https://doi.org/10.1097/DCR.0000000000000926.

25. Park SS, Park B, Park EY, Park SC, Kim MJ, Sohn DK, et al. Outcomes of high versus low ligation of the inferior mesenteric artery with lymph node dissection for distal sigmoid colon or rectal cancer. Surg Today. 2020;50(6): 560-8. https://doi.org/10.1007/s00595-019-01942-2.

26. Hajibandeh S, Hajibandeh S, Maw A. Meta-analysis and trial sequential analysis of randomized controlled trials comparing high and low ligation of the inferior mesenteric artery in rectal cancer surgery. Dis Colon Rectum. 2020;63(7):988-99. https://doi.org/10.1097/DCR.0000000000001693.

27. Zeng J, Su G. High ligation of the inferior mesenteric artery during sigmoid colon and rectal cancer surgery increases the risk of anastomotic leakage: a meta-analysis. World J Surg Oncol. 2018;16(1):157. Published 2018 Aug 2. https://doi.org/10.1186/s12957-018-1458-7.

28. Watanabe T, Muro K, Ajioka Y, Hashiguchi Y, Ito Y, Saito Y, et al. Japanese Society for Cancer of the Colon and Rectum (JSCCR) guidelines 2016 for the treatment of colorectal cancer. Int J Clin Oncol. 2018;23(1):1-34. https://doi. org/10.1007/s10147-017-1101-6

29. Cirocchi R, Randolph J, Cheruiyot I, Davies JR, Wheeler J, Lancia M, et al. Systematic review and meta-analysis of the anatomical variants of the left colic artery. Colorectal Dis. 2020;22(7):768-78. https://doi.org/10.1111/codi.14891.

30. Cirocchi R, Randolph J, Cheruiyot I, Davies RJ, Wheeler J, Gioia S, et al. Surgical anatomy of sigmoid arteries: a systematic review and meta-analysis. Surgeon. 2021:S1479-666X(20)30185-2.

\section{Publisher's Note}

Springer Nature remains neutral with regard to jurisdictional claims in published maps and institutional affiliations.

Ready to submit your research? Choose BMC and benefit from:

- fast, convenient online submission

- thorough peer review by experienced researchers in your field

- rapid publication on acceptance

- support for research data, including large and complex data types

- gold Open Access which fosters wider collaboration and increased citations

- maximum visibility for your research: over $100 \mathrm{M}$ website views per year

At $\mathrm{BMC}$, research is always in progress.

Learn more biomedcentral.com/submissions 